\title{
No caminho das setas: a produção de instrução ilustrada para crianças e as possibilidades de interpretação
}

\author{
In the way of arrows: the production of illustrated instruction \\ for children and its possibilities of interpretation
}

Rafaella Lopes P. Peres, Silvio Barreto Campello

ilustração instrucional, representação gráfica, interpretação infantil instructional illustration, graphic representation, child interpretation

\begin{abstract}
Este artigo propõe uma reflexão no âmbito das instruções ilustradas para crianças, considerando questões de interpretação de representações gráficas e do uso que fazem de instruções sequenciais. Descreve parte inicial de uma pesquisa de doutorado, com experimentos de observação de alunos da Educação Infantil. O artigo busca entender como as crianças lidam com a representação pictórica: quais seus níveis de familiaridade, e quais as principais dificuldades de compreensão. Aponta como resultado principal o fato de que as crianças são capazes de decodificar significativamente a linguagem visual gráfica e possuem grande interesse por instruções ilustradas. Além da importância em estar atento às necessidades do usuário e suas atitudes ante a representação proporcionada para transmitir informação útil e significativa.
\end{abstract}

This article proposes a reflection in the field of illustrated instructions for children taking into consideration the interpretation of graphical representations and the children's use of sequential instructions. It describes the start-up of a doctoral research using observations in a classroom of an elementary school. The article pursuits the comprehension of how children deal whit pictoric representation: which are their levels of familiarity and their principal difficulties in the process of interpretation? It points, as a result, the fact that children are capable of decoding graphic visual language meaningfully and that they have a large interest in illustrated instructions. Besides that, it is important to be attentive to the users' necessities and to their attitudes towards the representation presented in order to convey useful and substantial information.

\section{Introdução}

Para Eiríksdóttir e Catrambone (2008), as instruções mais comuns fazem uso de imagem e texto para explicar uma atividade passo-apasso num processo linear. São materiais que se baseiam em desenhos para comunicar uma informação e usam o texto para direcionar e limitar as possibilidades de interpretação. Segundo Paul (2012), 
a maioria dos humanos prefere instruções apoiadas por figuras, presentes na vida das pessoas desde a infância. Como as crianças assimilam as diferentes fontes de informação disponíveis atualmente? Como constroem seus olhares e como lidam com a diversidade de formas, tipos e estilos de representação cada vez mais variados?

Apesar do escopo do Design da Informação crescer diariamente com as possibilidades das novas tecnologias, Richards (1998) afirma que até o ano 2000 os materiais instrucionais eram ainda negligenciados. E embora as instruções pictóricas estejam sendo cada vez mais empregadas para informar sobre o uso/manutenção de produtos e serviços, pouco tem sido investigado pelo ponto de vista da linguagem gráfica (sPinILlo, 2000). Assim, os interesses deste trabalho se voltam à interpretação da ilustração para identificação e operação de objetos, à compreensão de imagens bidimensionais, e em especial ao material instrucional ilustrado de procedimentos (intitulado por Spinillo (2000) seqüências pictóricas de procedimento), traduzido aqui em receitas ilustradas.

As instruções e documentos relacionados tem sua taxonomia fundamentalmente baseada em metáforas gráficas (RICHARDS,1998); a própria imagem oferta inúmeras possibilidades. Então, se a compreensão depende da interpretação, é necessário compreender ao que uma coisa se refere, como se refere, e com quais sistemas de regras faz essa referência, pois, conforme Goodman (1976), a interpretação dos símbolos depende do sistema escolhido pelo ilustrador para representar, e ainda mais das relações feitas entre aquele e o repertório do observador. Idéia que leva à uma série de esforços por descobertas que não pretendem limitar ou prédeterminar as soluções comunicativas do design pictóricos, mas oferecer aos produtores um ponto de partida sensível com expectativas de criação e refinamento como parte de um processo de negociação entre produtores e usuários (KENNEDY \& ROSS, 1975; HAALAND \& FUSSEL, 1976; FUGELSANG, 1973; ASHWIN, 1979; COOK, 1980; GOLDSMITH, 1980; BIEGER \& GLOCK, 1986; GANIER, 2004; SCHUMACHER, 2009; SPINILLO et al., 2012, entre outros). Uma preocupação com o uso que se faz da ilustração e a certeza de que escolhas feitas no processo de produção influenciarão o processo de recepção e os modos de interpretação.

\section{Escolha do material}

O processo de produção de uma ilustração supõe que decisões feitas de forma consciente aumentam a probabilidade de identificação e articulação das variáveis/caracteres internos da imagem ilustrada. Ou seja, as propriedades físicas das instruções determinam seus significados.

No caso das receitas ilustradas analisadas aqui, é possível perceber que a composição se utiliza da proximidade, similaridade, 
e expectativa do observador relativa ao posicionamento dos objetos, para indicar atividades específicas. Já que para representar idéias abstratas o ilustrador faz uso de uma gama de dispositivos que pretendem intensificar propriedades determinadas da ilustração (ASHWIN, 1979). Um exemplo interessante é o uso da narrativa simultânea - representação de um motivo em distintas posições na mesma ilustração, como é o caso da banana na Figura 1 - para representar movimento.

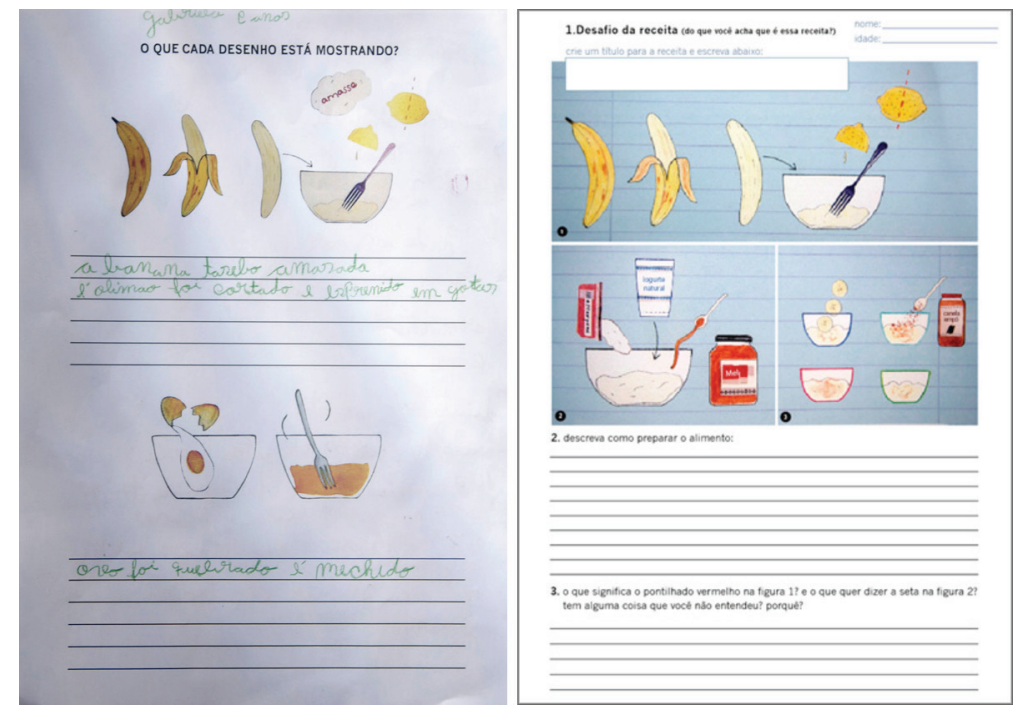

Figura 1 Dois questionários visuais, o primeiro aplicado na Waldorf e o segundo planejado para a Escola Parque, com pequenas diferenças contextuais

Em geral, os ilustradores parecem aceitar que a imagem pictórica deve ser tratada como um evento no espaço-tempo, e que portanto apresenta um movimento de transformação quando colocada em seqüência. O que sugere que a mudança da postura/posição dos objetos é um indício importante nas receitas ilustradas: uma travessa inclinada vertendo um líquido ou massa supõe que seu conteúdo está em movimento de queda, e que portanto a travessa está sendo usada. Ou seja, existe um tipo de expectativa, de informação implícita, que presume alguém fazendo uso dessa travessa, responsável por inclinar o objeto e realizar uma ação. Isso propõe que nossas experiências com objetos podem ser guardadas na forma de uma expectativa (GIBSON, 1996) e que quando os olhos se movem por uma cena essas expectativas direcionam a atenção aos elementos mais importantes e antecipam eventos.

Esses e outros preceitos foram levados em consideração na escolha do material a ser apresentado às crianças no estudo de recepção planejado. A seguir apresentaremos algumas justificativas para as decisões. 


\subsection{Questionário visual}

O primeiro instrumento compôs-se de um questionário visual (Figura 1) cujas seqüências pictóricas foram retiradas do livro The Silver Spoon for Children, da nutricionista infantil Amanda Grant (2009), idealizado especificamente para crianças. As ilustrações possuem uma variedade significativa de representações, relações de unidade por indicação, proximidade e semelhança de cor, e a idéia específica de continuidade no sentido de causa/efeito. Ao mesmo tempo que apresentam ingredientes supostamente conhecidos pelas crianças pernambucanas (a banana e o limão, por exemplo) e outros supostamente não familiares (como o mascarpone, tipicamente italiano).

Nessas seqüências, as ilustrações estão dispostas horizontalmente e respeitam o direcionamento de leitura ocidental com números como guias de leitura. Optou-se neste estudo por expor as imagens isoladas dos textos com o intuito de enfatizar dispositivos de ênfase (pontilhados de corte na cor vermelha), assim como dispositivos simbólicos (setas de direcionamento, posicionamento de utensílios, setas de indicação, entre outros); em tamanho satisfatório para a visualização de cor, textura, e outros elementos importantes.

A Figura 1 apresenta dois questionários distintos. No da primeira escola Waldorf, as seqüências estavam fora de seu contexto integral, apresentando apenas uma parte da receita. O intuito era priorizar a descrição das crianças em relação às representações de prosseguimentos e dispositivos simbólicos de representação de ação e direção (imagem da esquerda). Na segunda, Escola Parque, planeja-se apresentar a receita na íntegra (imagem da direita) por conta de comentários das crianças da Waldorf $\mathbf{1}$.

\subsection{Receita completa | grupo de discussão}

Um segundo instrumento foi elaborado com uma receita completa (formato A3) para apresentação em grupo de discussão. Neste material - num segundo momento - também foram excluídas as identificações textuais, e recolocado o ingrediente gengibre, anteriormente excluído por ser considerado fora do repertório infantil, com o intuito de desafiar as crianças.

A exclusão do texto objetivou verificar a capacidade de identificação de símbolos icônicos não familiares, como a representação do trigo por um ramo, ou da gema com um círculo amarelo dentro de uma forma de ovo pontilhada. Sendo mantido no entanto, o texto de identificação do açúcar (ver Figura 2) por sua representação abstrata, pois segundo

2 llustradora francesa formada em artes aplicadas, mestre em multimídia, com ateliê de ensino de desenho para crianças. Goldsmith (1980), a falta de familiaridade ou a dificuldade de identificação de uma imagem podem ser auxiliadas pelo texto.

A receita escolhida para o grupo de discussão (Figura 2) é uma adaptação da ilustração de Emilie Boudet ${ }^{2}$ no livro La cousine des paresseuses (JACKSON, 2005). Foi selecionada por ser uma receita 
3 Retirado do site <http:// escolawaldorfrecife.com/ about>, no link 'Pedagogia Waldorf' - acesso em 15 maio 2012. supostamente popular: bolo de chocolate, que possuísse alguma provocação: uso de utensílios peculiares (como a forma de cupcakes), e representações mais simples e abstratas (como do açúcar). E, apesar de requerer a presença de dispositivos simbólicos, dicas de separação, de seqüencialidade, representações de movimento, e outros elementos importantes na interpretação de procedimentos seqüenciais, também existiu uma preocupação inicial com o grau de complexidade que as crianças seriam capazes de compreender. Por isso procurou-se uma receita com poucos ingredientes e poucas variações de traço e cores.

A análise observou as características visuais das receitas escolhidas sob o ponto de vista das 9 categorias apontadas por Spinillo ${ }^{3}$ como relevantes no estudo de instruções pictóricas. Observou-se que neste caso a informação (1) inventarial é apresentada concomitantemente à (2) operacional, (3) descritiva e (4) espacial. Com o uso de todas as formas de informação espacial: localização, orientação e até mesmo composição (distribuição da massa em forma específica, por exemplo). E que apesar de apresentar informação (5) contextual pontual, com imagens resultantes de cada etapa, não apresenta informação contextual final (não vemos o bolo pronto). Essa ausência é pertinente aqui, pois permite propor a dedução do tipo de alimento que se quer preparar. O que ajuda na percepção das relações entre o que as crianças conhecem como procedimento culinário real, e as representações expostas.

É perceptível também o uso constante, não só nesta receita, de informações de causa e efeito - (6) covariantes, notadas por exemplo na etapa 2 da Figura 2, com o uso das setas indicando união e mistura de dois ingredientes (ovo e açúcar) que compõem um creme amarelo que dará origem à massa.

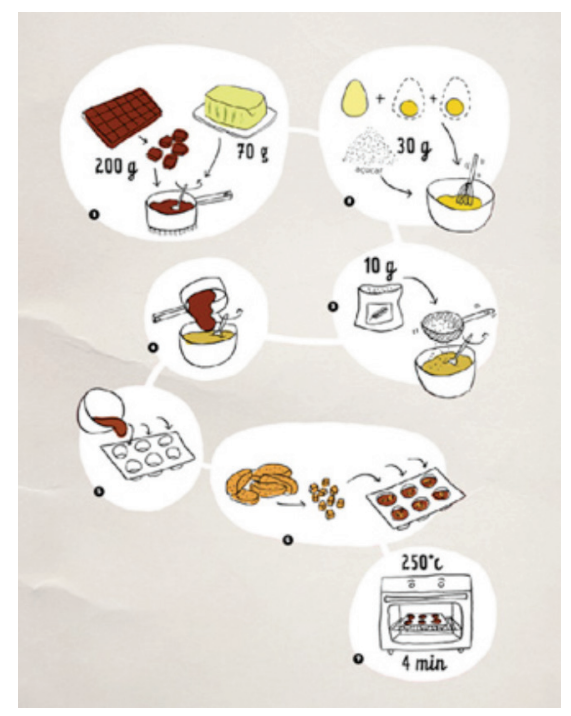

Figura 2 Receita em formato A3 para grupo de discussão com crianças de 8 a 9 anos 
Retirado do site <http:// escolawaldorfrecife.com/ about>, no link 'Pedagogia Waldorf' - acesso em 15 maio 2012.

5 Retirado do site: <http:// www.escolaparquedorecife. com.br/?page>, no link "Proposta" - acesso em 12 maio 2013.
São também encontradas informações (7) temporais e (8) qualificantes: a primeira para indicar as seqüências de passos (aqui se dá por meio das dicas de espaço, e/ou das ligações de grupos por apenas um caminho possível, e/ou pelo uso de números contínuos); e a segunda para especificar modos de feitura e limites, como as quantidades de cada ingrediente. As informações (9) enfáticas, neste caso, aparecem no uso das setas de direcionamento e indicação, que determinam qual o lugar de cada coisa; assim como no uso da cor vermelha para destacar o lugar de corte dos alimentos (Figura 1).

\section{Caminho do estudo}

Tendo como objeto de estudo a instrução ilustrada, o objetivo desta pesquisa foi observar a recepção e interpretação desse tipo de material por crianças de 8 e 9 anos para inferir características gráficas importantes e também familiaridade e dificuldades de compreensão das instruções. Para averiguação foi planejada uma pesquisa de campo de caráter exploratório com abordagem qualitativa, que delineou a observação de dois grupos de crianças de diferentes escolas pernambucanas, a Escola Waldorf do Recife e a Escola Parque de Jaboatão dos Guararapes.

A pedagogia da escola Waldorf se apóia no pensamento antroposófico que tem como premissa de aprendizagem a experimentação concreta ${ }^{4}$. Com um contexto de ensino bastante específico que prioriza o contato direto com a prática, as atividades de manuseio e o conhecimento empírico; e oferece aulas de culinária semanais.

Já a Escola Parque segue o referencial teórico de Paulo Freire, com a crença de que os alunos se preparam para o exercício da cidadania interagindo criticamente com a realidade, vivenciando experiências e decidindo por meio da reflexão $0^{5}$. E apesar de não oferecer atualmente aulas de culinária, os participantes tiveram recentemente atividades ligadas ao campo da culinária e da alimentação: palestras e degustação de alimentos. Portanto, os dois grupos de crianças estão familiarizados com o tema.

As atividades com as crianças foram planejadas em 3 etapas:

- apresentação do projeto e dos preceitos da pesquisa para os coordenadores e professores responsáveis, entrega dos termos de livre consentimento aos pais e alunos, e demais documentações necessárias para validação dos trâmites entre as instituições de ensino. E apresentação do pesquisador e explicação das atividades aos alunos participantes;

- entrega dos questionários visuais (material impresso em folha A4) às crianças, com duas seqüências de procedimento ilustradas, para descrição (individual) da imagem e os 
processos inferidos: percepções, interpretações e opiniões sobre as ilustrações e as representações simbólicas;

- apresentação de receita ilustrada (impressa em tamanho A3), na forma de grupo de discussão, incitando a reflexão sobre a imagem, para exposição pelas crianças de noções de seqüencialidade, de procedimento, de um passo após o outro, assim como do entendimento de outros tipos de representações simbólicas.

A segunda e a terceira etapas, de caráter etnográfico, foram planejadas de acordo com a realidade de cada escola e o momento de realização do estudo de recepção, ainda que levando em consideração preceitos padrões e o mesmo intuito: discutir a respeito das representações expostas pelo material oferecido e observar os elementos gráficos mais significativos e as dificuldades encontradas.

Os registros foram feitos por meio de anotações e fotos do momento da recepção e dos comentários feitos pelas crianças. Sendo também considerados os espaços da atividade, o grau de interesse e a realidade escolar dos participantes.

Assim, a primeira experiência de observação aconteceu na Escola Waldorf - com 13 alunos da $3^{\underline{a}}$ série - após uma das aulas de culinária, com o intuito de questionar, observar e compreender a dinâmica das aulas e especialmente a influência da experiência prática na compreensão da representação seqüencial. As duas atividades foram realizadas no horário completo de uma aula: 50 minutos.

Primeiro aplicou-se o questionário com as seqüências de procedimento e depois realizou-se o grupo de discussão com a receita em formato A3. Durante as discussões as crianças demonstraram grande interesse e solicitaram a realização de outros afazeres relacionados ao material em questão, como desenhar e/ou escrever sobre a receita. Diante do entusiasmo, a pesquisadora aproveitou a atividade extra para gerar discussões individuais com o intuito de colher informações mais específicas de cada criança. No fim, foi realizada uma entrevista semi-estruturada com a professora responsável, numa espécie de sessão pós-observação para retomar apontamentos e discutir a experiência de forma mais geral.

$\mathrm{Na}$ Escola Parque, o material também foi produzido de acordo com conversas com a coordenadora da Educação Infantil, e previamente apresentado para avaliação dos responsáveis pelo grupo de participantes - 10 alunos do $4^{\mathrm{O}}$ ano. E 50 minutos também foram cedidos para aplicação das atividades e devidas observações, porém por motivos além de nosso controle -, este segundo estudo ainda não pôde ser realizado. 


\section{Resultados parciais}

Os dados colhidos neste estudo corroboram e ao mesmo tempo contestam as expectativas iniciais, ao trazerem à tona uma variedade de interpretações ligadas ao repertório imagético das crianças e as experiências possibilitadas pelos espaços de aprendizagem.

Em atividade, o indivíduo se apodera das ferramentas psicológicas disponíveis e ulteriormente as internaliza. Dessa forma, observando a atividade e seu desenvolvimento ao longo do tempo, torna-se possível observar alterações no processo mental dos indivíduos. Como conseqüência, a unidade de análise passa a ser a atividade prática na qual o indivíduo se engaja (BARRETo CAMPELLO, 2005).

O estudo sugere que essas crianças ao terem contato com a experiência concreta iniciam um processo de familiarização e de habituação com as ações constituintes da atividade em questão. Apenas com a experiência empírica como fonte de saber, são capazes de divagar sobre a atividade por meio de representações tanto lingüísticas e gestuais, quanto visuais. Ao descreverem as ações e/ou explicarem os desenhos, as crianças gesticulam e fazem movimentos concernentes à atividade culinária. O que propõe a construção de um tipo de conhecimento experimental que é transposto para o campo da representação. Por isso supõe-se que no caso do público infantil a representação próxima do real, que Ashwin (1979) chama de naturalismo e outros autores denominam realismo, pode ser positiva.

No caso dos códigos estéticos, a experiência em relação a prérequisitos talvez seja mais direta e freqüente, pois na criança, o gesto, a articulação de sons e o desenho são percepções precedentes. Nessa direção, Oliveira (1998), defende que um repertório motor, visual e verbal é construído gradativamente com a compreensão simbólica determinada pelo conhecimento da representação e o entendimento do que ela quer dizer. Por isso, considera-se que o contexto em que as imagens são apresentadas influencia os resultados, e que a vivência dos alunos da Waldorf com as aulas de culinária semanais, tem impacto direto na interpretação das representações pictóricas relativas, especialmente, ao mesmo tema.

Os gestos, os termos lingüísticos utilizados na atividade prática se repetem na descrição das imagens durante a discussão em grupo, a noção de seqüencialidade é relacionada com os procedimentos que eles já conhecem. E a partir da "nova" representação visual à qual são apresentados, constroem outros entendimentos relacionados não só ao tema, como também à linguagem visual de forma geral. O que leva a crer que as crianças geram conhecimento e transformam suas atitudes constantemente, mesmo que de forma inconsciente. E o contato com determinadas atividades é capazes de elaborar um vocabulário específico com novos termos relativos à elas. 
De uma maneira geral, as crianças observadas se mostraram aptas a interpretar as imagens e suas relações no contexto das seqüências de procedimento, com deduções específicas ao fazer culinário: "eu achei que poderia ser claras em neves, mas não é porque a mistura está amarela, então colocaram a gema também”. Ou com estranhamento pela ausência de um ingrediente supostamente comum em determinados tipos de receitas: "essa receita é meio estranha, né? Só poder ser um brownie. É, é um brownie: não tem nem fermento!”. Assim como identificações imediatas de continuidades, seguimento de passos consecutivos, e a compreensão de elementos representativos de movimento, calor, união, entre outros. Assim, a questão da maior ou menor familiaridade como suporte para a compreensão das representações (GOLDSMITH, 1980), pode ser observada nos estudos de recepção.

Outro ponto identificado por Goldsmith (1980) é o contexto de leitura e a experiência do observador como determinantes da forma como o produtor deverá representar algo que não possui representação direta. A representação da noção de frio, por exemplo, não possui uma imagem específica relacionada à ele, mas sintomas que aceitadamente o identificam. Nas receitas ilustradas a mesma coisa acontece no momento de representação de movimento ou técnicas específicas que exigem um esforço de síntese. Portanto, o produtor da imagem, na representação de situações que implicam uma capacidade de observação e um conhecimento específico, deve reconhecer a significância das dicas informativas ao mesmo tempo que considera a capacidade do observador em percebe-las.

As crianças observadas nesse estudo demonstram uma compreensão exata dessas representações, inclusive com diferenciações específicas referentes ao uso dos mesmos dispositivos simbólicos em diferentes contextos. Elas são capazes, por exemplo, de determinar diferentes usos da seta:

Ah, essa seta aqui diz que é pra colocar o chocolate e a manteiga aqui nessa bacia. Essa outra também pra juntar o ovo e o açúcar; esses traços aqui são porque estão misturando o ovo com o açúcar nessa bacia aqui, essa outra seta aqui diz que é pra colocar uma massa dentro da outra e depois mexer bem, essa aqui diz que ta pronto e é pra colocar no forno ... (falas dos alunos na escola Waldorf).

A partir da observação percebe-se que a atenção do observador pode ser direcionada de diversas formas: pelo tom, pela cor, tamanho, direção; a relação entre a posição e a borda da imagem, isolamento; ou por dispositivos lineares. A receita A3 é um exemplo, já que sua organização é feita com um contorno em volta dos grupos de atividade, etapas, ou passos da receita. E a ilustradora se utilizou de um contraste figura/fundo, cores e formas, para agrupar os elementos em momentos específicos e determinantes, direcionando a seqüência 
a partir das ligações desse contorno. Apesar de ter contado com o padrão de leitura ocidental como uma premissa, a partir do momento que o observador entende onde está o começo, percebe-se que seu olhar é direcionado pelas conexões entre os "balões". De um para outro, num caminho até o último "balão". No momento de discussão as crianças descreveram os passos apontando cada etapa de acordo com esse caminho.

Portanto, as características das ilustrações instrucionais, e a disposição dos componentes da imagem, apresentam significados importantes ao determinarem a ordem de seqüência de uma atividade específica, e orientarem o seguimento de passos e procedimentos que dependem um do outro para serem realizados satisfatoriamente.

A partir do estudo também é possível perceber um interesse considerável das crianças pela aula de culinária, e pelos materiais relacionados à ela; e que independente dos procedimentos seguidos e da forma como ela é elaborada, a maior parte dos alunos se empenha e se dedica às ações envolvidas. A aplicação do questionário visual confirmou esse interesse. Parece existir uma vontade direcionada que interfere nas ações e operações ligadas ao tema, tanto que os exercício renderam mais do que o esperado gerando questionamentos calorosos por mais de um encontro, e considerações enfáticas sobre a realização da receita. Os exercícios trouxeram informações relevantes quanto à capacidade de interpretação das crianças, com descrições claras sobre os significados das imagens e os procedimentos a serem seguidos.

Quando me sentei com as crianças para discutir sobre a receita impressa em 'grande formato', e pedi que elas comentassem sobre a imagem, todos quiseram participar e iniciaram uma conversação empolgada sobre o que estavam observando. Foram poucas as interferências ou direcionamentos realizados. Imediatamente eles quiseram saber do que era a receita, deixando claro que aquilo era uma receita. "Claro que é uma receita, mas é do quê?" Começaram a especular: podia ser de brownie, todo mundo concordou. Mas também podia ser de cupcake, alguém falou. Ou um simples bolo de chocolate. "Não, a forma é de bolo pequenininho, pode ser um muffin, eu acho que é um muffin de chocolate”. A partir daí descreveram os desenhos, passo por passo. Cada um falando de uma etapa, e complementando o que o outro dizia. "Ah, aqui ta derretendo o chocolate. Mas o que é esse número aqui? São as gramas, 200 gramas de manteiga pra derreter junto do chocolate. Olha, aqui é um ovo, mais duas gemas, é pra mexer tudo junto com açúcar. Aqui tá peneirando a farinha, e no fim coloca no forno". E assim foram elaborando deduções utilizando termos como derreter, juntar, colocar na bacia, mexer bem, misturar, primeiro, depois, aí ... vez ou outra alguma coisa chamava a atenção de algum deles e a pergunta era direcionada pra um detalhe do desenho, mas no geral a receita foi descrita exatamente na seqüência em que as ações deveriam ser realizadas (anotações do caderno de campo da pesquisadora). 
Um dos alunos mais novos quis escrever a lista de ingredientes e os modos de feitura da receita, e numerou as etapas de acordo com o redesenho que fez dela. Ao mesmo tempo em que redesenhava o fogão, justificava as mudanças de traço e estilo pelo incômodo que sentiu ao perceber o fogão da receita como uma cara com uma 'bocona' aberta (rever Figura 2). "Aliás, tia, o que é este ' ${ }^{\circ} \mathrm{C}$ ' depois do 250 ?".

\section{Considerações finais}

No Design da Informação a transformação de dados em informação válida e significativa precisa estar atenta ao conhecimento das necessidades do usuário com um mínimo entendimento de suas atitudes (SHEDROFF, 2010). Destarte, os resultados desta observação estão ligados à compilação de material instrucional ilustrado para crianças. Um conhecimento mais aprofundado não só com relação às características formais e elementos constitutivos das ilustrações instrucionais, como também do processo de recepção infantil e seus modos interpretativos. E, uma prática de pesquisa - baseada em grupo focal - que se aplique da melhor forma à realidade infantil. Pois, aceito o pressuposto de Libâneo (2004) que o ensino é caracterizado pela organização social da apropriação, e que a apropriação é o processo que tem por resultado a reprodução das capacidades e procedimentos de conduta humana historicamente formados (LEONTIEV, 1992); supõe-se que o contato das crianças com material instrucional ilustrado é capaz de possibilitar a formação de sujeitos pensantes e críticos aptos a internalizar conceitos, representações e informações simbólicas que se constituem em instrumentos para lidar com a realidade.

Se o intuito maior da pesquisa (não só deste artigo) é encontrar fatores da linguagem visual que influenciam no processo de apreensão da informação, percebeu-se pertinente observar o processo de recepção e interpretação das crianças no momento em que ele ocorre. Assim como observar as discussões geradas pelas diversas possibilidades de representação simbólica contida nas seqüências instrucionais.

De qualquer forma, pesquisas referentes ao Design da Informação e o público infantil são relevantes e de interesse do campo por possibilitarem a ampliação de seus resultados a outros veículos de comunicação com o público infantil; enfatizando a importância da consideração do público no momento de produção do artefato instrucional, assim como do conhecimento e entendimento das possibilidades representativas e suas combinações.

É imprescindível, no entanto, apontar que os experimentos realizados aqui não dão conta de responder completamente as questões levantadas. Foram apresentados apontamentos iniciais sobre as características relevantes da produção instrucional 
ilustrada no âmbito da recepção e interpretação infantil, hipóteses e direcionamentos concernentes à tipos de ilustração, elementos representativos, formas de composição das receitas ilustradas especificamente, e mais amplamente das Seqüências Pictóricas de Procedimentos. Tudo isso precisa de aprofundamento.

Por fim, concordamos com Goldsmith (1980), que a análise da ilustração pode trazer considerações extremamente relevantes para a produção e consumo de peças gráficas, pois pudemos observar - ainda que em pequena instância - que o usuário realmente reage aos sinais gráficos, às imagens em termos dos significados intencionados, e aos significados de acordo com as experiências previas relevantes e seu julgamento enquanto observador.

\section{Agradecimento}

Sem a autorização e cordialidade dos professores e alunos (assim como responsáveis) das escolas visitadas, essa pesquisa não teria sido realizada, por isso, agradecemos a participação e o interesse. Agradecemos também aos funcionários da UFPE envolvidos no processo e à CAPES por subsidiar a pesquisa de doutorado aqui referida.

\section{Referências}

Artigos em revistas acadêmicas/capítulos de livros

ASHWIN, C. (1979). The ingredients of style in contemporary illustration: a case study. In: Information Design Journal, v. 1, p. 51-67.

BARRETO CAMPELlo, s. (2009). Aprendizagem mediada por computador. In: Selected Readings in Information Design: communication, technology, history and education, Curitiba.

BIEGER, G. R. \& GLOCK, M. D. (1986). Comprehending spatial and contextual information in picture-text instructions. Journal of Experimental Education, 54, 181-188.

Cook, в. (1980). Picture Communication in Papua New Guinea. Education Broadcasting International.

Fuglesang, A. (1973). Applied Communication in Developing Countries: Ideas \& Observations. Uppsala: The Dag Hammarskold Foundation.

GANIER, F. (2004). Les apports de la psychologie cognitive a la conception d'instructions Procedurales. InfoDesign Revista Brasileira de Design da Informação 1, v. 1, p. 16-28.

GIBSON, J. J. (1966). The problem of temporal order in stimulation and perception. Journal of Psychology, 62, 141-149.

GOLDSMITH, E. (1980). Comprehensibility of illustration: an analytycal model. In: Information Design Journal, v. 1, n. 3, p. 204-213. 
Goodman, N. (1976). Languages of art: an approach to a theory of symbols. Indianápolis, IN: Hackett.

GRANT, A. (2009). The silver spoon for children: favorite Italian recipes. NY: Phaidon.

HaAland, A., \& Fussell, D. (1976). Communicating with Pictures in Nepal: Report of a study by NDS and UNICEF. Kathmandu: NDS and UNICEF. Document Number) concept paper for researchers and health policy decis JACKSON, R. (2005). La cousine des paresseuses. Paris: Marabout.

KENNEDY, J. M. \& ROSS, A. S. (1975). Outline picture perception by the Songe of Papua. Perception, 4, 391-406.

LEONTIEV, A. N. (1992). Uma contribuição à teoria do desenvolvimento da psique infantil. In: VIGotski, L.S., LURIA, A . R. \& LEONTIEV, A. N. Linguagem, desenvolvimento e aprendizagem. São Paulo: Ícone Editora.

RICHARDS, C. (1998). Getting the picture: Diagram design and the information revolution. In: Information Design Journal, v. 9, n. 2-3, pp. 87-110 (24).

SCHumacher, P. (2009). Pictorial Communication in developing countries: a literature review. In: Centre for the Public Awarness of Science. Austrália.

SPINILlO, C. G.; SOUZA, J. M. B.; STORCK, G., R. \& SMYTHE, K. C. A. S. (2012). Efeito de tempo de apresentação na compreensão de preferência em instrução visual animada. In: Anais do P\&D Design (CD-room).

\section{Livros e materiais não publicados}

SPINILLO, C. (2000). An analytical approach to procedural pictorial sequences. Tese de doutorado não publicada. Departamento de Tipografia Comunicação Gráfica. Universidade de Reading, Grã-Bretanha.

\section{Textos publicados na internet}

EIRÍKSDÓtTtr, E. \& CATrambone, R. (2008). Using Instructions in Procedural Tasks. School of Psychology, Georgia Institute of Technology, usa. Disponível em: <csjarchive.cogsci.rpi.edu/proceedings/2007/docs/p959.pdf> - acesso em 20 de maio de 2012.

LIBÂNEO, J. C. (2004). A Didática e a aprendizagem do pensar e do aprender - a teoria histórico-cultural da atividade e a contribuição de Vasili Davidov. In: Revista Brasileira de Educação [online], n.27, set/out/nov, p.5-24. Disponível em: <www.scielo.br/pdf/rbedu/n27/n27a01.pdf > - acesso em 20 de maio de 2012.

OLIVEIRA, S. R. (1998). Leitura de imagens para a educação. Tese de doutorado apresentada à Pontifícia Universidade Católica de São Paulo. São Paulo. Disponível em: <www.pergamumweb.udesc.br/dados-bu/oooooo/ oooooooooooC/00000C74.pdf> - acesso em 10 de maio de 2013.

PAul, Y. (2012). Pictorial Instructions: what are they for? Disponível em: <http:// techwhirl.com/pictorial-instructions-what-good/> - acesso em 5 de maio de 2013.

SHEDROFF, N. (1999). Information interaction design: a unified field theory of design. Disponível em: <http://www.nathan.com/thoughts/unified>. Acesso em: 05 fev. 2010. 


\section{Sobre os autores}

Rafaella Lopes P. Peres

<rafaellaperes@hotmail.com>

Mestre, UFPE, Brasil

\section{Silvio Barreto Campello}

<sbcampello@gmail.com>

PhD, UFPE, Bolsista do CNPq, Brasil 